\title{
Airflow Distribution Measurements around the Human Body Using a Thermal Manikin by Particle Image Velocimetry
}

\author{
Yuki Arinami1 ${ }^{*}$, Shin-Ichi Akabayashi', Kunio Mizutani2 ${ }^{2}$ Jun Sakaguchi' ${ }^{3}$ \\ ${ }^{1}$ Graduate School of Science and Technology, Niigata University, Niigata, Japan \\ ${ }^{2}$ Department of Architecture, Tokyo Polytechnic University, Tokyo, Japan \\ ${ }^{3}$ Department of International Studies and Regional Development, Faculty of International Studies and Regional Development, \\ University of Niigata Prefecture, Niigata, Japan \\ Email: *arinamiy@eng.niigata-u.ac.jp
}

How to cite this paper: Arinami, Y., Akabayashi, S.-I., Mizutani, K. and Sakaguchi, J. (2017) Airflow Distribution Measurements around the Human Body Using a Thermal Manikin by Particle Image Velocimetry. Journal of Flow Control, Measurement \& Visualization, 5, 65-72.

https://doi.org/10.4236/jfcmv.2017.53005

Received: June 8, 2017

Accepted: July 9, 2017

Published: July 12, 2017

Copyright (c) 2017 by authors and Scientific Research Publishing Inc. This work is licensed under the Creative Commons Attribution International License (CC BY 4.0).

http://creativecommons.org/licenses/by/4.0/

\begin{abstract}
The human body is a heat source in a room. As the human body has a complex shape, it is difficult to accurately measure the airflow distribution around the human body using a conventional anemometer. This study measured the airflow distribution around a thermal manikin acting as a human body by visualization and particle image velocimetry (PIV). The thermal manikin was $1700 \mathrm{~mm}$ in height, and its surface temperature was set to $30^{\circ} \mathrm{C}$. The experiments were performed in the conditions when the manikin was seated on a chair. The ambient air temperature and wind velocity were experimental variables. The airflow distribution around the manikin was reported by considering the relationships between convection and ambient wind velocity. There were no differences in the airflow distribution around the manikin due to the ambient air temperature when the wind velocity in the chamber was set as 1.0 $\mathrm{m} / \mathrm{s}$. Hence, it was assumed that the ambient wind velocity was dominant in this condition. Various airflow distributions were formed around the manikin due to the difference between the body surface temperature and the ambient air temperature in the case where the wind velocity in the chamber was set to approximately equal to $0.0 \mathrm{~m} / \mathrm{s}$.
\end{abstract}

\section{Keywords}

Thermal Manikin, Heat Convection, Airflow Distribution, Particle Image Velocimetry, Natural Convection

\section{Introduction}

Recently, computational fluid dynamics (CFD) has been used to predict the in- 
door distribution of airflow, contaminants, and temperatures. The distributions greatly vary depending on the room shapes, heat source locations, window openings, and HVAC inlet and outlet ports. It is necessary to understand the thermal convection around a human body, which acts as a heat source in a room, in detail. This is necessary to predict the indoor air quality (IAQ) and thermal environment around an occupied zone in depth. Gao et al. calculated air flow, temperature, $\mathrm{CO}_{2}$ concentration distribution for seated virtual thermal manikin using CFD [1]. They compared CFD results with experiment at some points. It is difficult to accurately measure the airflow distribution around the human body using a conventional anemometer because of the complex shape of the human body.

In previous studies, the focus of research reports is an airflow distribution of subregions (head, abdomen, legs, etc.) around the thermal manikin. Yousaf et al. (2011) simulated and measured thermal plume around human head using thermal manikin with CFD and particle image velocimetry (PIV) [2]. They measured air flow distributions around human head using two cameras of which measurement area size is about $500 \times 500 \mathrm{~mm}$. Cao et al. (2014) measured air distribution around human body in aircraft cabin using PIV [3]. This measurement was performed at 5 sub-regions of which size is $975 \mathrm{~mm} \times 650 \mathrm{~mm}$. Marr et al. (2005) measured velocimetry field in breathing zone of a thermal breathing manikin using a time-resolved PIV system [4]. This measurement area size is about $100 \mathrm{~mm} \times 100 \mathrm{~mm}$. However, there is very limited research on airflow distributions around the entire body of a manikin.

In this study, the airflow distributions around the entire body of a thermal manikin were measured by flow visualization and PIV. PIV is a noncontact method that simultaneously measures the airflow velocity at multiple points, and therefore PIV is preferred over conventional anemometers. However, PIV was used for relatively small areas (e.g., a square of area $500 \times 500 \mathrm{~mm}$ ). Recently, PIV can be measure airflow distributions in and around buildings for larger areas (Akabayashi et al., 2013 [5]). In this study, the ambient temperature and wind velocity were experimental variables. The air flow distribution around the manikin considering relationships between convection and ambient wind velocity were reported.

\section{Experimental Method}

\subsection{Experimental Set up}

The experiment was performed in an artificial climate chamber $(5000 \mathrm{~mm}$ width, 11,000 $\mathrm{mm}$ length, and $3000 \mathrm{~mm}$ height). The chamber could adjust the room temperature from $20^{\circ} \mathrm{C}$ to $35^{\circ} \mathrm{C}$ in increments of $0.5^{\circ} \mathrm{C}$. The wind velocity in the chamber was adjusted from $0.1 \mathrm{~m} / \mathrm{s}$ to $2.7 \mathrm{~m} / \mathrm{s}$. The experimental set up is illustrated in Figure 1. The thermal manikin illustrated in Figure 2 was 1700 $\mathrm{mm}$ in height. The surface temperature of the manikin was set to $30^{\circ} \mathrm{C}$. In this paper, surface temperature of thermal manikin was homogeneous distribution. However, surface temperature of real human body has inhomogeneous distri- 


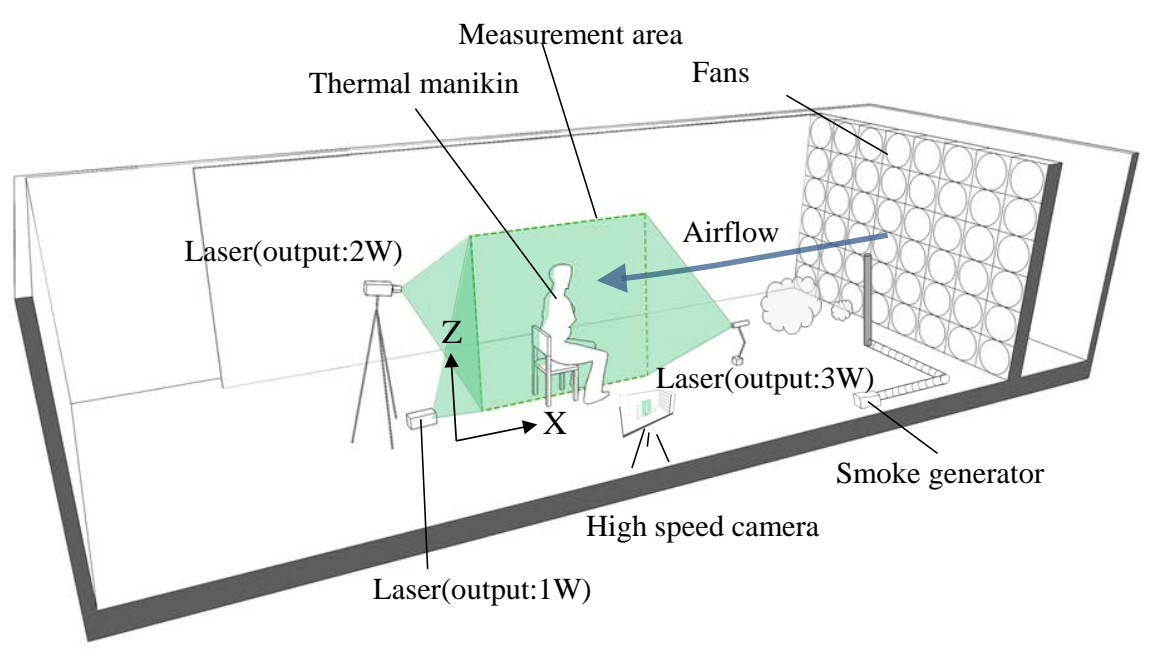

Figure 1. The experimental set up.

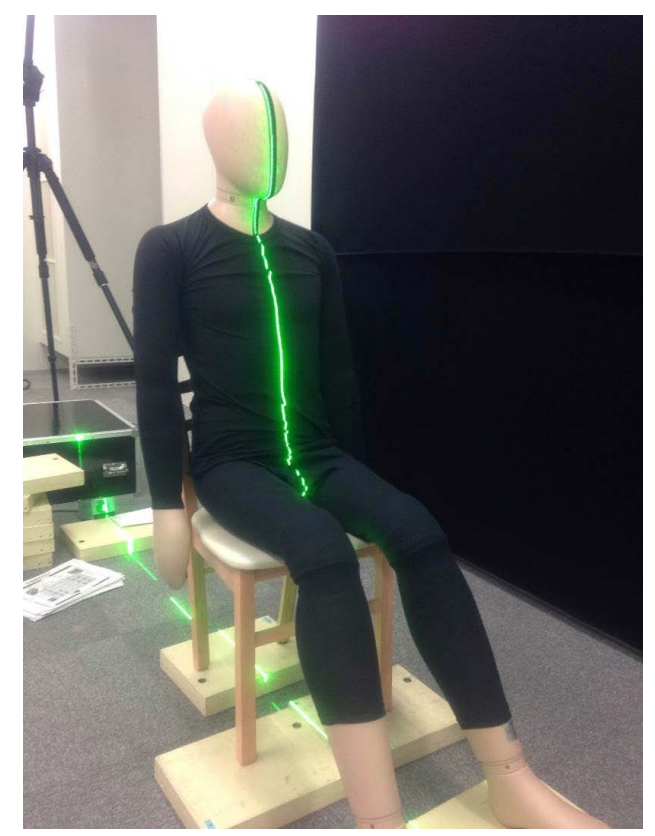

Figure 2. The thermal manikin.

bution. Consideration of human body surface temperature distribution is a next subject.

The experiment was performed in the condition when the manikin was seated in a chair. The manikin was dressed in a black T-shirt and tights in order to reduce the reflection of laser light sheets at its surface. In this experiment, multiple lasers irradiated the manikin in order to eliminate shadows. Three lasers with outputs of $1 \mathrm{~W}, 2 \mathrm{~W}$, and $3 \mathrm{~W}$ were used. Three laser light sheets were adjusted on the same plane.

\subsection{Experiment Cases}

The experiment cases included the following. In this paper, the main experimental variable was ambient wind velocity and lower one was ambient air tem- 
perature. The ambient wind velocity around the manikin was set to $1.0 \mathrm{~m} / \mathrm{s}$ in case 1 or approximately equal to $0.0 \mathrm{~m} / \mathrm{s}$ in case 2 (it is written as “ $\sim 0.0 \mathrm{~m} / \mathrm{s}$ " in the following sentences). In lower case 1 , the ambient air temperature was $20^{\circ} \mathrm{C}$, which was $10^{\circ} \mathrm{C}$ lower than the surface temperature of the manikin. In lower case 2 , the ambient air temperature was $30^{\circ} \mathrm{C}$, which was equal to the surface temperature of the manikin. In lower case 3, the ambient air temperature was $35^{\circ} \mathrm{C}$, which was $5^{\circ} \mathrm{C}$ higher than the surface temperature of the manikin. All six cases were indicated in Table 1.

\subsection{Experiment Equipment}

Three lasers were used to perform the visualization experiment. Three laser light sheets were adjusted on the same plane. A $3 \mathrm{~W}$-output laser irradiated the whole manikin from its front to visualize the entire measurement area uniformly. A 2 $\mathrm{W}$ and a $1 \mathrm{~W}$-output laser were placed behind the manikin to irradiate it from the back. The high-speed camera used in the experiment was a Photron FASTCAM-SA3. The tracers consisted of flame-retardant smoke made by a smoke generator: DAINICHI PORTA SMOKE PS-2002. The particle size wasseveral $10 \mu \mathrm{m}$ or more.

\subsection{Experimental and Analysis Methods}

The calibration value or the conversion value between the pixel length and the real size length was $1.6935 \mathrm{~mm} /$ pixel as indicated in Table 2. A recognizable plate was installed and photographed at a real distance on the measurement area to calculate the calibration value. The frame rate of the high-speed camera (measurement interval) was $250 \mathrm{fps}(4 \mathrm{~ms})$ in case 1 and $60 \mathrm{fps}(17 \mathrm{~ms})$ in case 2 . Each measurement took $22 \mathrm{~s}$ in case 1 and $45 \mathrm{~s}$ in case 2 . The smoke generator was placed in the windward direction so that it did not influence the airflow to the maximum extent possible, and it performed seeding. The PIV analysis method was a direct cross-correlation method. We had performed sub-pixel estimation and confirmed that there was no displacement peak near integer pixel values. Uncertainty of PIV had been reported that an accuracy of $5 \%$ to $10 \%$ could be achieved for room airflow measurement using the two component PIV technique [6] [7]. Although the mean displacement of tracer was different on a

Table 1. The experimental cases.

\begin{tabular}{|c|c|c|c|c|}
\hline \multicolumn{2}{|c|}{ Case } & \multirow{2}{*}{$\begin{array}{l}\text { Ambient wind } \\
\text { velocity }[\mathrm{m} / \mathrm{s}]\end{array}$} & \multirow{2}{*}{$\begin{array}{c}\text { Ambient air } \\
\text { temprature }\left[{ }^{\circ} \mathrm{C}\right]\end{array}$} & \multirow{2}{*}{$\begin{array}{l}\text { Surface temprature of the } \\
\text { manikin }\left[{ }^{\circ} \mathrm{C}\right]\end{array}$} \\
\hline & $1-1$ & & & \\
\hline \multirow[t]{3}{*}{ Case 1} & $1-2$ & 1.0 & 30 & \multirow{5}{*}{30} \\
\hline & $1-3$ & & 35 & \\
\hline & $2-1$ & & 20 & \\
\hline \multirow[t]{2}{*}{ Case 2} & $2-2$ & $\begin{array}{l}\text { approximately } \\
\text { equal to } 0.0\end{array}$ & 30 & \\
\hline & $2-3$ & & 35 & \\
\hline
\end{tabular}


Table 2. Parameters of the PIV analysis.

\begin{tabular}{ccc}
\hline Case & Case 1 & Case 2 \\
\hline Ambient wind velocity & $1.0 \mathrm{~m} / \mathrm{s}$ & approximately equal to $0.0 \mathrm{~m} / \mathrm{s}$ \\
Measurement area size & \multicolumn{2}{c}{$1700 \mathrm{~mm} \times 1700 \mathrm{~mm}$} \\
Image size & \multicolumn{2}{c}{1024 pixel $\times 1024$ pixel } \\
Calibration value & \multicolumn{2}{c}{$1.6935 \mathrm{~mm} /$ pixel } \\
Measurement time & $22 \mathrm{sec}$ & $45 \mathrm{sec}$ \\
Measurement interval & $4 \mathrm{~ms}(250 \mathrm{fps})$ & $17 \mathrm{~ms}(60 \mathrm{fps})$ \\
Interrogation region & 15 pixel $\times 15$ pixel & 13 pixel $\times 13$ pixel \\
Search region & \pm 5 pixel $\times \pm 5$ pixel & \pm 5 pixel $\times \pm 5$ pixel \\
\hline
\end{tabular}

case by case, these were about 1.1 pixels in this paper. Therefore the uncertainty of velocity measurement was estimated to be about $9 \%$ of the mean velocity. One of the purposes of this study is to organize the basic data for comparison with CFD analysis by PIV measurement. For the purpose, the subject on this paper is how to measure airflow distribution around entire real scale size human body. Therefore, we examined ways to perform a wide range of PIV measurements compared with previous studies. We are planning that the uncertainty and accuracy of the PIV measurement experiment are to be evaluated in next study (Table 3).

\section{Results and Discussions}

\subsection{Results of PIV Analysis in Case 1}

In the case of the wind velocity in the chamber set at $1.0 \mathrm{~m} / \mathrm{s}$, the airflow rose around the thermal manikin. The airflow along the chest and abdomen of the manikin was formed and moved upwards at a velocity ranging $0.1-0.3 \mathrm{~m} / \mathrm{s}$ in each case. Vortices were formed around the back of the chair. At each ambient temperature, there were almost no differences in the airflow distribution (Figure 3).

\subsection{Results of PIV Analysis in Case 2}

In case $2-1$, when the wind velocity in the chamber setting was $\sim 0.0 \mathrm{~m} / \mathrm{s}$, convection occurred along the head, chest, and abdomen of the manikin. The airflow ascended at a velocity ranging $0.08-0.15 \mathrm{~m} / \mathrm{s}$ in $\mathrm{X}=500-1000 \mathrm{~mm}$, and $\mathrm{Z}=$ 600 - $1200 \mathrm{~mm}$ (Figure 4).

In case 2-2, the airflow was almost stopped around the manikin in $X=600$ $800 \mathrm{~mm}$, and $\mathrm{Z}=600-1100 \mathrm{~mm}$ because there was no difference between the surface temperature of manikin and the ambient temperature. Airflow ascended slightly along the chest at a velocity ranging $0.01-0.03 \mathrm{~m} / \mathrm{s}$. In $\mathrm{X}=0-1700 \mathrm{~mm}$ and $\mathrm{Z}=1400-1700 \mathrm{~mm}$, the airflow moved horizontally.

In case 2-3, the airflow moved downwards at a velocity ranging $0.01-0.08 \mathrm{~m} / \mathrm{s}$ around the manikin in $\mathrm{X}=0-800 \mathrm{~mm}$ and $\mathrm{Z}=0-1700 \mathrm{~mm}$, because the surface 
Table 3. The experimental equipment.

\begin{tabular}{cc}
\hline High-speed camera: Photron FASTCAM-SA3 1024 pixels $\times 1024$ pixels \\
\hline DPGL-3W LD Excitation, Nd: YAG/YVO ${ }_{4}$ Laser \\
Wavelength: $532 \mathrm{~nm}$, Output: $3 \mathrm{~W}$ \\
Continuous light (Modulation range: $0-30 \mathrm{kHz})$ \\
DPGL-2W LD Excitation, Nd: YAG/YVO $\mathrm{Laser}^{-}$ \\
Wavelength: $532 \mathrm{~nm}$, Output: $2 \mathrm{~W}$ \\
Continuous light (Modulation range: $0-30 \mathrm{kHz})$ \\
G1000 LD Excitation, Nd: YAG/YVO $\mathrm{Laser}^{-}$ \\
Wavelength: $532 \mathrm{~nm}$, Output: $1 \mathrm{~W}$ \\
Continuous light (Modulation range: $0-30 \mathrm{kHz})$ \\
Camera control Photron FASTCAM Viewer ver.3.3.8 \\
PIV analysis Flow-Expert ver1.25
\end{tabular}

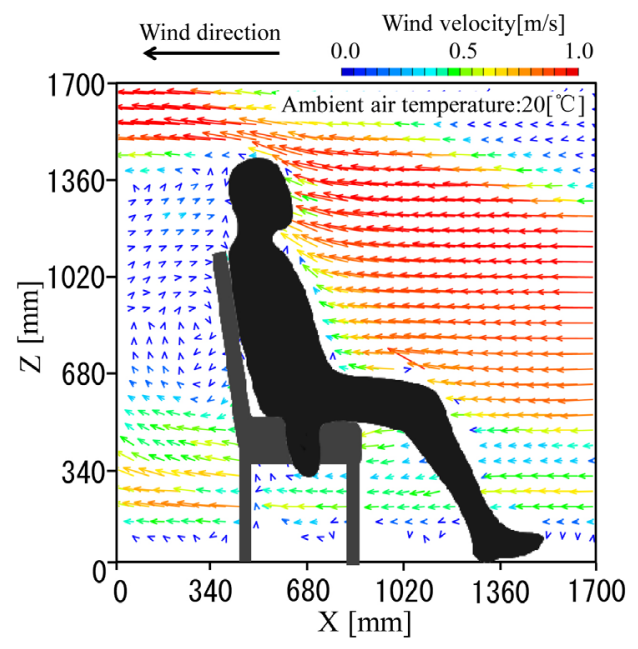

(a) Case 1-1.

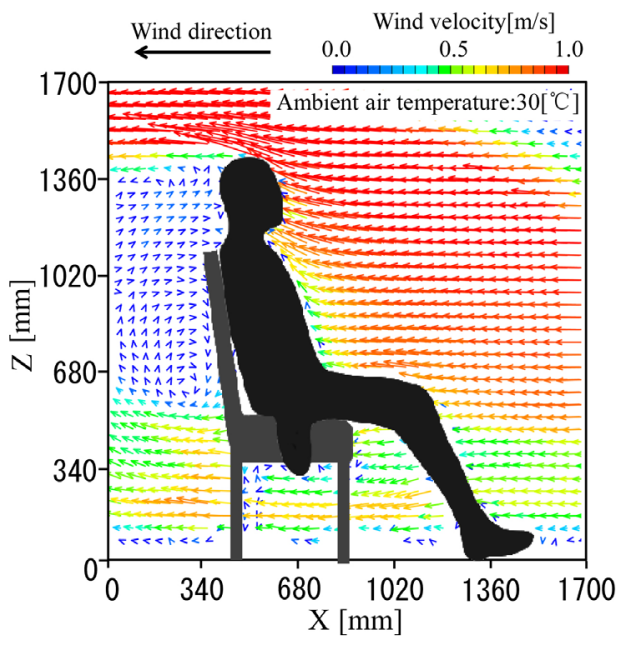

(b) Case 1-2.

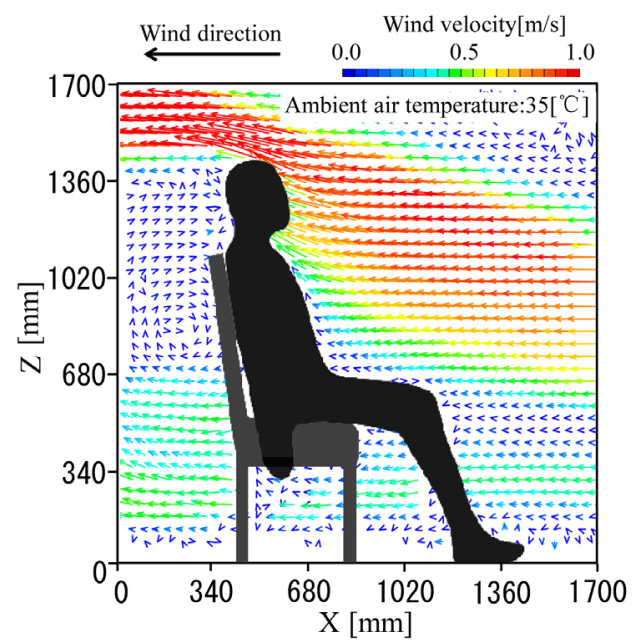

(c) Case 1-3.

Figure 3. Distribution of the mean airflow velocity vector around the manikin. Ambient wind velocity is $1.0 \mathrm{~m} / \mathrm{s}$. (a) Ambient air temperature is $20^{\circ} \mathrm{C}$. (b) Ambient air temperature is $30^{\circ} \mathrm{C}$. (c) Ambient air temperature is $35^{\circ} \mathrm{C}$. 


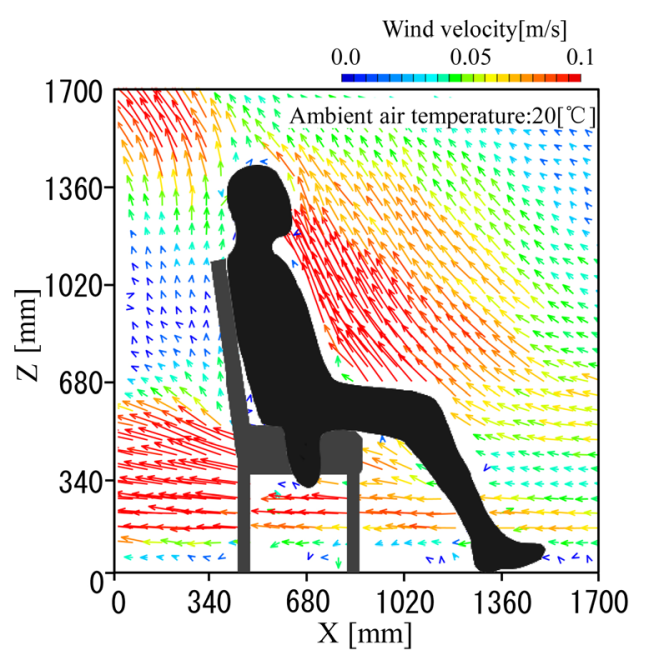

(a) Case 2-1.

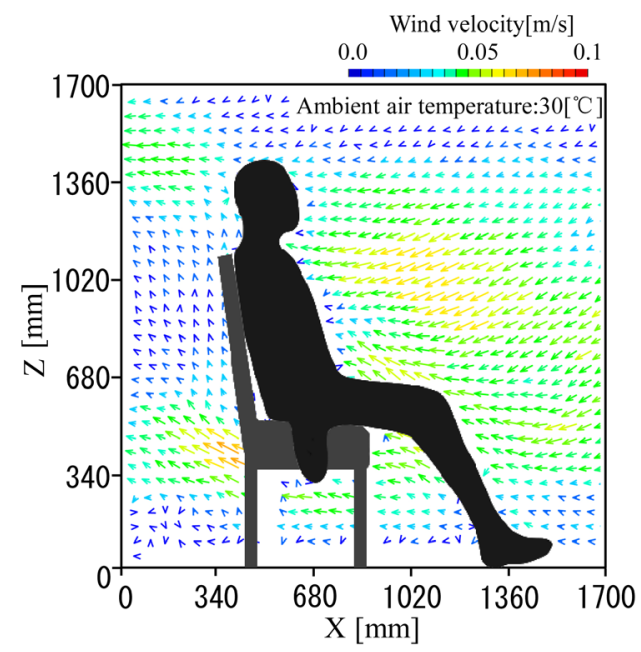

(b) Case2-2.

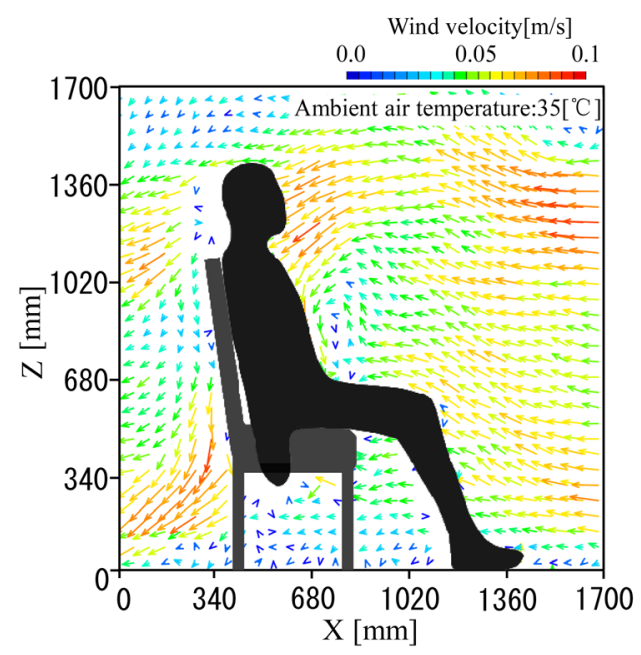

(c) Case 2-3.

Figure 4. Distribution of the mean airflow velocity vector around the manikin. Ambient wind velocity is approximately equal to $0.0 \mathrm{~m} / \mathrm{s}$. (a) Ambient air temperature is $20^{\circ} \mathrm{C}$. (b) Ambient air temperature is $30^{\circ} \mathrm{C}$. (c) Ambient air temperature is $35^{\circ} \mathrm{C}$.

temperature of themanikin was lower than the ambient air temperature. The vortices were formed around the front of the manikin at a velocity ranging 0.01 $0.04 \mathrm{~m} / \mathrm{s}$ in $\mathrm{X}=700-900 \mathrm{~mm}$ and $\mathrm{Z}=700-1000 \mathrm{~mm}$.

\section{Conclusion}

There was no difference in the airflow distribution when the wind velocity in the chamber was set to $1.0 \mathrm{~m} / \mathrm{s}$. Therefore, it was assumed that the ambient wind velocity was dominant in this condition. Various airflow distributions were formed around the manikin in the case when the wind velocity in the chamber was set to $\sim 0.0 \mathrm{~m} / \mathrm{s}$. This was because of the difference between the body surface temperature and the ambient air temperature.

\section{References}

[1] Gao, N. and Niu, J. (2004) CFD Study on Micro-Environment around Human Body 
and Personalized Ventilation. Building and Environment, 39, 795-805. https://doi.org/10.1016/j.buildenv.2004.01.026

[2] Yousaf, R., Wood, D., Cook, M., Tong, Y., Hodder, S., Loveday, D. and Passmore, M. (2011) CFD and PIV Based Investigation of Indoor Airflows Dominated by Buoyancy Effects Generated by Occupancy and Equipment. Proceedings of Building Simulation 2011: 12th Conference of International Building Performance Simulation Association, Sydney, 14-16 November 2011, 1465-1472.

[3] Cao, X., Liu, J., Pei, J., Zhang, Y., Li, J. and Zhu, X. (2014) 2D-PIV Measurement of Aircraft Cabin Air Distribution with a High Spatial Resolution. Building and Environment, 82, 9-19. https://doi.org/10.1016/j.buildenv.2014.07.027

[4] Marr, D., Khan, T., Glauser, M., Higuchi, H. and Zhang, J. (2005) On Particle Image Velocimetry (PIV) Measurements in the Breathing Zone of a Thermal Breathing Manikin, American Society of Heating, Refrigerating and Air-Conditioning Engineers, Inc. ASHRAE Transactions, Volume 111, Part 2. www.ashrae.org

[5] Akabayashi, S., Oshima, T., Arinami, Y., Okubo, H., Yang, X. and Sakaguchi, J. (2013) Japan. Journal of Environmental Engineering (Transactions of AIJ), 690, 631-638.

[6] Cao, X., Liu, J.N. and Chen, Q. (2014) Particle Image Velocimetry Measurement of Indoor Airflow Field: A Review of the Technologies and Applications. Energy and Buildings, 69, 367-380. https://doi.org/10.1016/j.enbuild.2013.11.012

[7] Sun, Y. and Zhang, Y. (2007) An Overview of Room Air Motion Measurement: Technology and Application. HVAC\&R Research, 13, 929-950.

https://doi.org/10.1080/10789669.2007.10391463

\section{Submit or recommend next manuscript to SCIRP and we will provide best service for you:}

Accepting pre-submission inquiries through Email, Facebook, LinkedIn, Twitter, etc. A wide selection of journals (inclusive of 9 subjects, more than 200 journals) Providing 24-hour high-quality service User-friendly online submission system Fair and swift peer-review system Efficient typesetting and proofreading procedure Display of the result of downloads and visits, as well as the number of cited articles Maximum dissemination of your research work

Submit your manuscript at: http://papersubmission.scirp.org/

Or contact jfcmv@scirp.org 